\title{
FORMULATION AND INVITRO EVALUATION OF
} FAMCICLOVIR FLOATING TABLETS BY USING EFFERVESCENT TECHNOLOGY

\author{
Mr. Nagareddy ${ }^{1 *}$, Chandrasekhar Reddy ${ }^{1}$ and G. Vijay Kumar ${ }^{2}$ \\ ${ }^{1}$ LIOYD Laboratories Inc, Manila, Philipines. \\ ${ }^{2}$ Department of Pharmacy, KGR Institute of Technology and Management, \\ Keesara, MedchaL(D), Telangana, India.
}

\begin{abstract}
The purpose of this research was to develop a novel gastroretentive drug delivery system based on Effervescent technology for controlled delivery of active agent by using Famciclovir. Tablets were formulated by using direct compression, and evaluated for several pre compression and post compression evaluation studies including floating buoyancy studies and in vitro dissolution studies. Total six formulations F1-F6 floating tablets of Famciclovir was formulated using Effervescent floating technique, in which maximum drug release was shown in F6 formulation containing Guar gum as a rate retarding polymer. For the optimized formulation, stability studies were performed and it was identified that there was no change in the effect of drug release after the stability studies. Among all the rate retarding polymers we have used Guar gum shows better drug release upto 11 hours when compared with other polymers. So Guar gum was used in the formulations for formulating gastro retentive floating tablets. The marketed comparision for the optimized formulations were compared and the floating tablets were successfully retarded the drug release in $0.1 \mathrm{~N}$ HCL for 11 hours by using Effervescent floating Technique by using Guar gum.
\end{abstract}

Keywords: Famciclovir, Effervescent floating technique and Guar gum.

\section{INTRODUCTION}

Oral delivery of drugs is by far the most preferable route of drug delivery due to the ease of administration, patient compliance and flexibility in formulation, etc. From immediate release to site-specific delivery, oral dosage forms have really progressed.

One of the most feasible approaches for achieving a prolonged and predictable drug delivery profile in the GI tract is to control the gastric residence time (GRT) ${ }^{1}$ for example, drugs that are absorbed in the proximal part of the gastrointestinal tract, and drugs that are less soluble in or are degraded by the alkaline $\mathrm{pH}$ may benefit from prolonged gastric retention. In addition, for local and sustained drug delivery to the stomach and proximal small intestine to treat certain condition, prolonged gastric retention of the therapeutic moiety may offer numerous advantages including improved bioavailability and therapeutic efficacy, and possible reduction of the dose size.

\section{GASTRORETENTIVE DRUG DELIVERY SYSTEM}

Gastro retentive dosage form can remain in the gastric region for several hours and hence significantly prolong the gastric residence time of drugs.

Anatomically the stomach is divided into 3 regions: fundus, body, and antrum (pylorus). The proximal part made of fundus and body acts as a reservoir for undigested material, 
where as the antrum is the main site for mixing motions and act as a pump for gastric emptying by propelling actions ${ }^{3}$.

\section{OBJECTIVE OF THE STUDY}

Floating drug delivery systems (FDDS) have a bulk density less than gastric fluids and so remain buoyant in the stomach without affecting the gastric emptying rate for a prolonged period of time. While the system is floating on the gastric contents, the drug is released slowly at the desired rate from the system. After release of drug, the residual system is emptied from the stomach. This results in an increased GRT and a better control of the fluctuations in plasma drug concentration. So for increasing the gastric retention time of the some poorly acidic absorption drugs were selected for increasing the gastric retention time for increasing the bioavailability of Famciclovir. ${ }^{4}$

\section{MATERIALS AND METHODS}

Famciclovir obtained as a gift sample from Cadila pharmaceuticals, Xanthan gum, Guar gum, Citric acid, Sodium bicarbonate are prucased from Shreeji chemicals, Mumbai and all other chemicals and solvents used are from S.D fine chemicals, Mumbai.

\section{Preparation of Famciclovir Floating Tablets by Direct Compression Method ${ }^{5}$}

All ingredients were collected and weighed accurately. Drug with polymers were sifted and passed through sieve \#40 and then the remaining excipients were rinsed over, after pre blending all ingredients in mortar for 15 minutes. Then magnesium stearate and talc were added and blended for 5-6 minutes, lubricated powder was compressed under $8 \mathrm{~mm}$ punch of tablet punching machine, (Cadmach model DC16 16-Station Tablet Press). The composition of different formulations is shown in the above tables.

\section{Evaluation Parameters of Famciclovir Floating Tablets ${ }^{6-10}$}

\section{Weight variation}

Twenty tablets from each formulation were selected at random and average weight was determined. Then the individual tablets were weighed and were compared with average weight.

\section{Hardness}

The hardness of the tablet from each formulation was determined using Pfizer hardness tester.

\section{Friability}

Friability of the tablets was determined using Roche Friabilator. This device subjects the tablets to the combined effect of abrasion and shock in a plastic chamber revolving at $25 \mathrm{rpm}$ and dropping the tablets at a height of 6 inches in each revolution. Pre weighed sample of 20 tablets was placed in the friabilator and were subjected to 100 revolutions. Tablets were dedusted using a soft muslin cloth and reweighed. The friability ( $f$ ) is given by the formula.

$$
\text { Friability }(f)=\left(1-\frac{W_{o}}{W}\right) \times 100
$$

Where,

$\mathrm{W}_{0}$ is weight of the tablets before the test and $\mathrm{W}$ is the weight of the tablet after the test.

\section{Thickness and diameter}

The thickness and diameter of tablet was carried out using Digital caliper. Five tablets were used for the above test from each batch and results were expressed in millimeter.

\section{Drug content}

10 tablets were selected randomly and powered using mortar and pestle then one tablet equivalent of the API, extraction was carried out using $0.1 \mathrm{~N} \mathrm{HCL}$. The concentration was determined spectrophotometrically at $224 \mathrm{~nm}$ against appropriate blank. Calculate the drug content by using UV spectrophotometry using $0.1 \mathrm{~N} \mathrm{HCL}$.

\section{In-vitro buoyancy studies}

The in vitro floating behavior of the tablets was studied by placing them in $100 \mathrm{ml}$ beaker 100 $\mathrm{ml}$ of $0.1 \mathrm{~N} \mathrm{HCl}\left(\mathrm{pH} 1.2,37^{\circ} \mathrm{C}\right)$. The time, tablet required for the emerge on the surface is floating lag time (FLT) or buoyancy lag time $(B L T)$. And the time tablet constantly float on the surface of the medium is called total floating time (TFT).

$$
\text { Swelling index }=\frac{\text { Final weight }- \text { Initial weight }}{\text { Initial weight }} \times 100
$$

\section{In-vitro dissolution studies ${ }^{11-15}$}

The release rate of formulated floating tablets were determined using the United States Pharmacopoeia (USP) dissolution testing apparatus II. The dissolution test was performed using $900 \mathrm{ml}$ of $0.1 \mathrm{~N} \mathrm{HCL}$, at $37 \pm$ $0.5^{\circ} \mathrm{C}$ and $50 \mathrm{rpm}$. The samples were taken at pre-selected time intervals with replacement of equal volume of dissolution medium, the samples were analyzed using UV Spectroscopy at $224 \mathrm{~nm}$. 


\section{RESULTS AND DISCUSSION}

FTIR Interpretation of Famciclovir

FTIR spectrum for Famciclovir indicated characteristics peaks belonging to measure functional groups such as principal peaks at wave numbers $1210.83 \mathrm{~cm}^{-1}$ (C-O stretching), $1727.48 \mathrm{~cm}^{-1}(\mathrm{C}=\mathrm{O}$ stretching $), 2308.15 \mathrm{~cm}$ ${ }^{1}(\mathrm{O}=\mathrm{C}=\mathrm{O}$ stretching $), \quad 961.28 \quad \mathrm{~cm}^{-1}(\mathrm{C}=\mathrm{C}$ bending) and $3227.54 \mathrm{~cm}^{-1}(\mathrm{O}-\mathrm{H}$ Stretching).

The optimized formulation also comprises of the same characteristics peaks as that of the pure Famciclovir indicates that the pure drug and excipients haven't any interactions.

From the compatibility studies it was concluded that the functional groups that were presented in the pure drug were present in the optimized formulation with very minute changes, from this we can concluded that the drug and excipients have no interactions.

\section{DSC Studies}

Thermogram of pure drug showed a sharp endothermic peak at $104.88^{\circ} \mathrm{C}$, which corresponds to its melting point. Famciclovir and Excipients mixture also showed endothermic peak at $104.02^{\circ} \mathrm{C}$, which corresponds to the melting point of the drug. The evaluation of thermograms revealed no interaction between the drug and the excipients. From the thermograms, it was evident that the melting point of Famciclovir has not changed after it was formulated as a floating matrix tablet.

\section{In-Vitro Drug Release Studies In-vitro drug release data of Famciclovir floating tablets by effervescent technique} From the drug release studies of the gastro retentive floating tablets of Famciclovir formulated by effervescent technique the maximum amount of drug release was found in F6 formulation containing Guar gum (30\%) as a rate retarding polymer as it has higher efficiency for retarding the drug release in the dissolution medium.

As Guar Gum has higher viscosity nature the formulation with higher concentration of Guar Gum maintains sustained drug release.

So the drug release kinetics were studied for the F6 formulation, and it follows zero order drug release and the drug release mechanism was found to be non-ficikian transport mechanism.

\section{CONCLUSION}

Total 6 formulations were formulated using Famciclovir using Effervescent floating technique. All the formulations were evaluated for the pre compression and post compression parameters and all the formulations shows acceptable limits. The in vitro drug release profiles of the formulations F1-F6 the maximum drug release was found in the F6 formulation containing guar gum $(30 \%)$ as a rate retarding polymer with more than $11 \mathrm{hrs}$ floating lag time. So formulation F6 was considered as the optimized formulation, and from the studies it is concluded that Famciclovir can be formulated as GRDDS with guar gum as polymer by effervescent technique.

Table 1: Composition of Famciclovir floating tablets by Effervescent technique

\begin{tabular}{|c|c|c|c|c|c|c|}
\hline Ingredients(mg) & F1 & F2 & F3 & F4 & F5 & F6 \\
\hline Famciclovir & 250 & 250 & 250 & 250 & 250 & 250 \\
\hline Xanthan Gum & 50 & 100 & 150 & - & - & - \\
\hline Guar Gum & - & - & - & 50 & 100 & 150 \\
\hline PVP K30 & 6 & 6 & 6 & 6 & 6 & 6 \\
\hline MCC & 130 & 80 & 30 & 130 & 80 & 30 \\
\hline NAHCO3 & 50 & 50 & 50 & 50 & 50 & 50 \\
\hline Citric acid & 5 & 5 & 5 & 5 & 5 & 5 \\
\hline Mg -stearate & 6 & 6 & 6 & 6 & 6 & 6 \\
\hline Talc & 3 & 3 & 3 & 3 & 3 & 3 \\
\hline Total wt (mg) & $\mathbf{5 0 0}$ & $\mathbf{5 0 0}$ & $\mathbf{5 0 0}$ & $\mathbf{5 0 0}$ & $\mathbf{5 0 0}$ & $\mathbf{5 0 0}$ \\
\hline
\end{tabular}


FTIR Spectroscopy

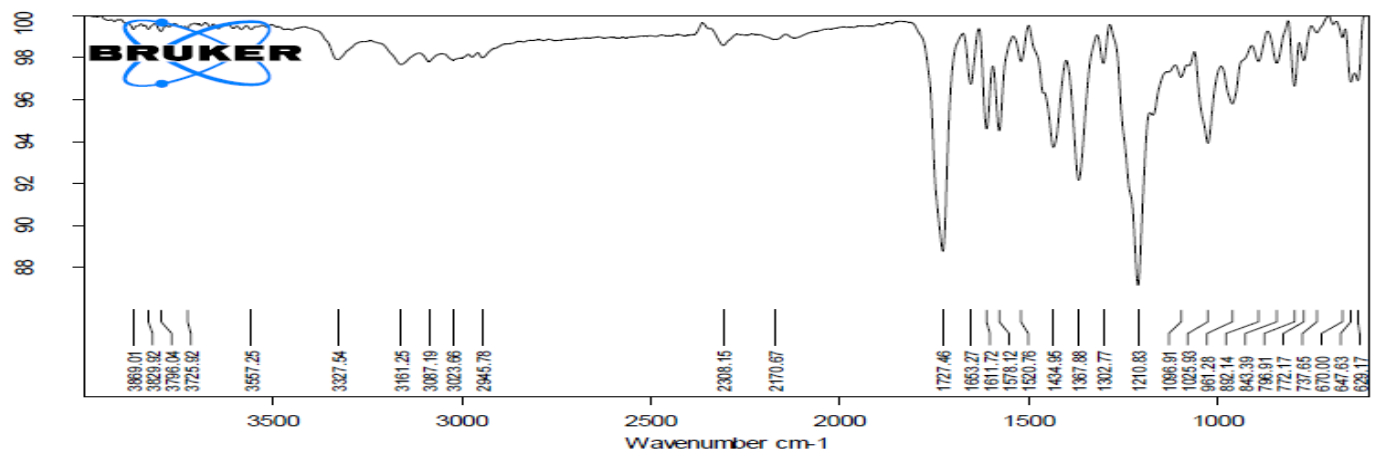

Fig. 1: IR spectra of Famciclovir

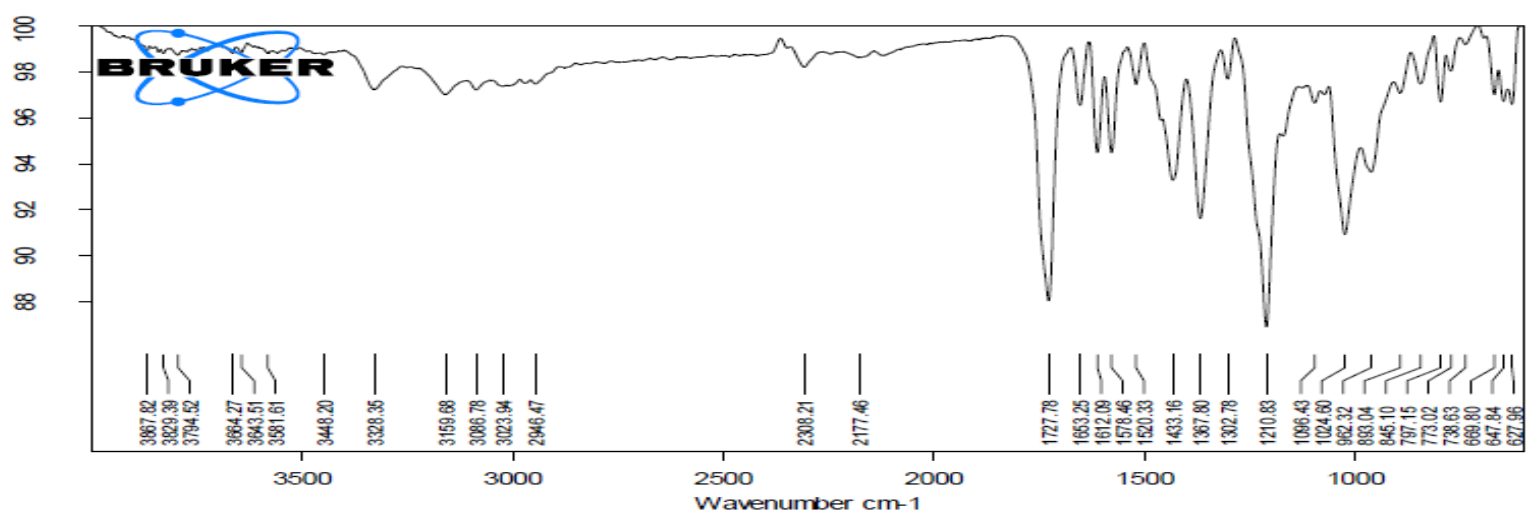

Fig. 2: FT-IR Spectra of Famciclovir and Excipients

DSC Studies

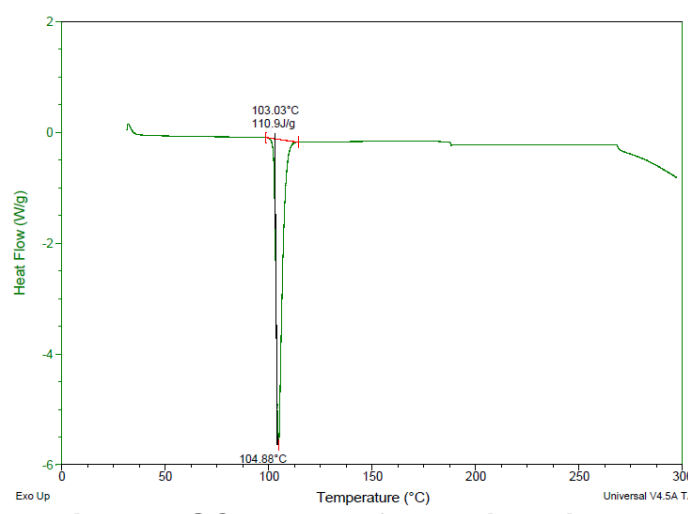

Fig. 3: DSC Graph of Famciclovir

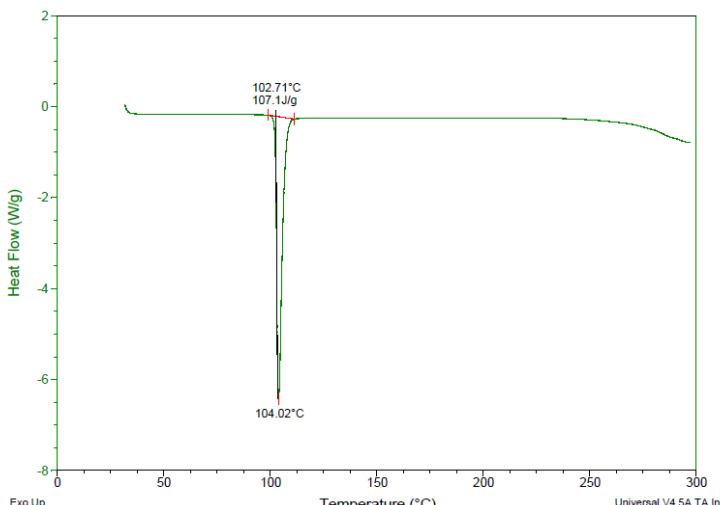

Fig. 4: DSC Graph of Famciclovir and Excipients 
Table 2: Post-compression parameters of Famciclovir floating tablets

\begin{tabular}{|c|c|c|c|c|c|c|}
\hline $\begin{array}{c}\text { Formulation } \\
\text { code }\end{array}$ & $\begin{array}{l}\text { Average wt in } \\
(\mathrm{mg}) \pm S D\end{array}$ & $\begin{array}{c}\text { Hardness } \\
\left(\mathrm{Kg} / \mathrm{cm}^{2}\right) \pm S D\end{array}$ & $\begin{array}{l}\text { Diameter } \\
(\mathrm{mm}) \pm \mathrm{SD}\end{array}$ & $\begin{array}{l}\text { Thickness } \\
(\mathrm{mm}) \pm S D\end{array}$ & $\begin{array}{l}\text { Friability } \\
(\%) \pm S D\end{array}$ & $\begin{array}{l}\text { Drug CU } \\
(\%) \pm S D\end{array}$ \\
\hline $\mathrm{F} 1$ & $500.2 \pm 0.25$ & $6.2 \pm 0.63$ & $12.02 \pm 0.63$ & $5.63 \pm 0.15$ & $0.18 \pm 0.08$ & $95.63 \pm 0.16$ \\
\hline $\mathrm{F} 2$ & $499.9 \pm 0.61$ & $6.3 \pm 0.52$ & $12.04 \pm 0.05$ & $6.96 \pm 0.18$ & $0.14 \pm 0.03$ & $95.29 \pm 0.52$ \\
\hline F3 & $500.1 \pm 1.42$ & $7.1 \pm 0.36$ & $12.12 \pm 0.09$ & $5.52 \pm 0.52$ & $0.52 \pm 0.36$ & $96.43 \pm 0.15$ \\
\hline $\mathrm{F} 4$ & $500.4 \pm 0.45$ & $6.8 \pm 0.05$ & $11.90 \pm 0.15$ & $5.18 \pm 0.05$ & $0.63 \pm 0.12$ & $94.14 \pm 0.30$ \\
\hline F5 & $499.5 \pm 0.52$ & $7.2 \pm 0.04$ & $12.02 \pm 0.1818$ & $5.63 \pm 0.06$ & $0.18 \pm 0.05$ & $98.96 \pm 0.15$ \\
\hline F6 & $501.5 \pm 0.52$ & $7.1 \pm 0.21$ & $12.04 \pm 0.74$ & $5.38 \pm 0.49$ & $0.74 \pm 0.06$ & $97.82 \pm 0.23$ \\
\hline
\end{tabular}

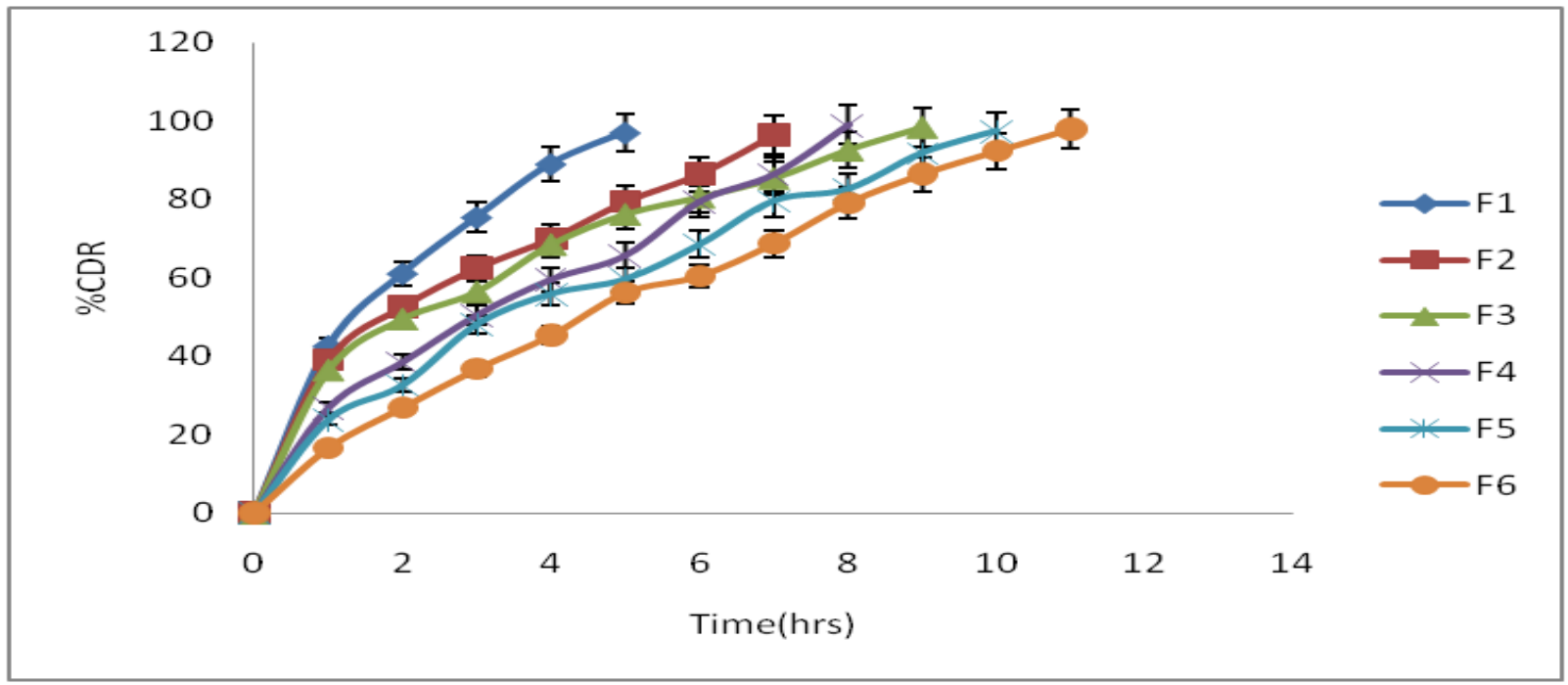

Fig. 5: In-vitro drug release profile of Famciclovir floating tablets of batches F1 to F6

\section{REFERENCES}

1. Garg S and Sharma S. Gatroretentive drug delivery system in: Drug delivery oral. Business Brief. Pharmatech. 2003;160-166.

2. Rouge N, Buri P and Doeilkar E. Drug absorbtion sites in the gastrointestinal tract and dosage forms for sitespecific delivery. Int $\mathrm{J}$ Pharm. 1996;136:117-139.

3. Fell JT, Whitehead $L$ and Collet $H$. Prolonged gastric retension using floating dosage forms. Pharm Technol. 2000;24(3):82-90.

4. Matharu RS and Sanghvi NM. Novel drug delivery system of captopril. Drug Dev Ind Pharm. 1992;18:15671574.

5. Fell JT. Delivery sytem for targeting to specific sites in the gastrointestinal tract. J Pharmacol.1999;51:41.

6. Baumgartner S, Kristil J, Vrecer F, Vodopivec $P$ and Zorko B. Optimization of floating matrix tablets and evaluation of their gastric residence time. Int $\mathrm{J}$ Pharm. 2000;195 (1-2):125-135.

7. Aulton ME. Pharmaceutics. The Science of Dosage Form Design.
Churchill Livingstone, London, Second Edition 2002.

8. Aulton ME. Pharmaceutics. The Science of Dosage Form Design. Churchill Livingstone, London, Second Edition 2002.

9. Oth $M$ and Franze $M$. The bilayer floating capsule: a stomach directed drug delivery system for misoprostol. Pharm Res. 1992;9(8):298-302.

10. Gergogiannins YS. Floating and swelling characteristic of various excipients used in controlled release technology. Drug Dev Ind Pharm. 1993;19(6):1061-1081.

11. Costa $P$ and Sousa LJM. Modelling and comparison of dissolution profiles, European Journal Pharmaceutical Sciences. 2001;13(2):123-133.

12. Yasmin Begum $M$, Avanthi J, Shwetha A, Madhuri T, Sudhakar M and Naveen D. Formulation and Evaluation of Sustained Release Floating Tablets of Loratadine. IJPSR. 2014;5(10):4375-4385.

13. Dash S, Murthy PN, Nath L and Chowdhury P. Kinetic modeling on drug release from controlled drug 
delivery systems. Acta Poloniae Pharmaceutica - Drug Research. 2010;67: 217-223.

14. Maninderjit Kaur. Overview on Stability
2013;3(4):1231-1241.

15. ICH Q1A (R2). Stability testing guidelines: Stability testing of new drug substances and products. $\mathrm{ICH}$ Steering Committee. 2003. 